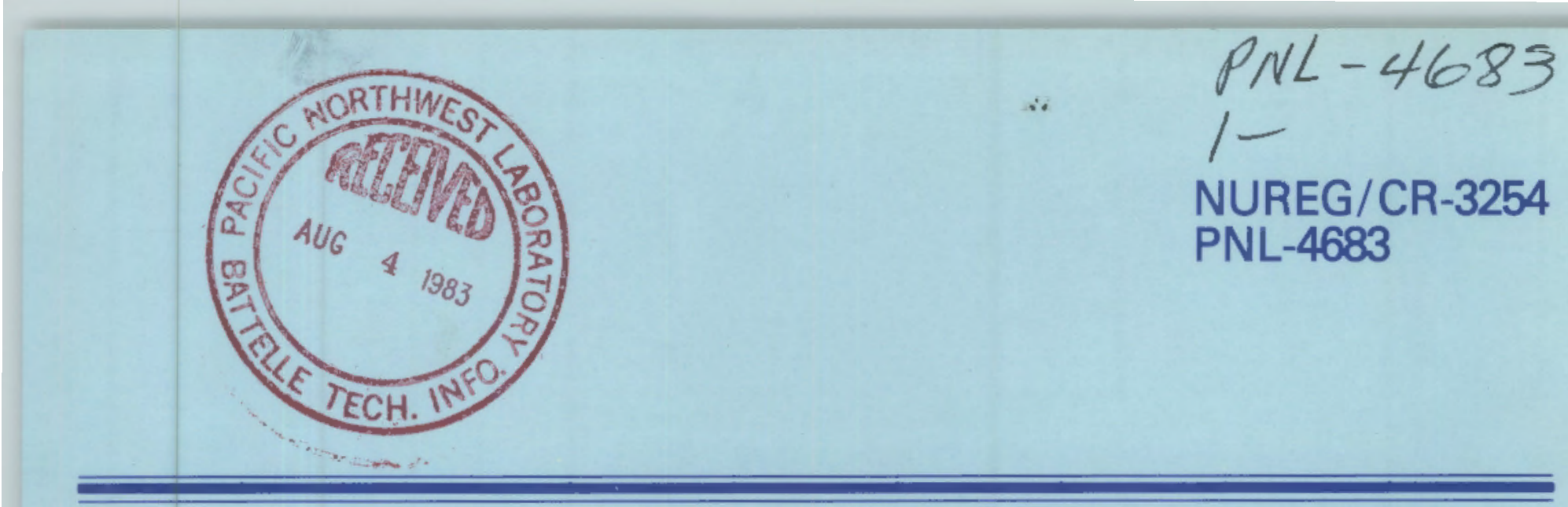

\title{
Licensee Programs for Maintaining Occupational Exposure to Radiation As Low As Is Reasonably Achievable
}

Prepared by L. H. Munson

Pacific Northwest Laboratory Operated by

Battelle Memorial Institute

Prepared for U.S. Nuclear Regulatory Commission 


\section{NOTICE}

This report was prepared as an account of work sponsored by an agency of the United States Government. Neither the United States Government nor any agency thereof, or any of their employees, makes any warranty, expressed or implied, or assumes any legal liability of responsibility for any third party's use, or the results of such use, of any information, apparatus, product or process disclosed in this report, or represents that its use by such third party would not infringe privately owned rights.

\section{Availability of Reference Materials Cited in NRC Publications}

Most documents cited in NRC publications will be available from one of the following sources:

1. The NRC Public Document Room, 1717 H Street, N.W. Washington, DC 20555

2. The NRC/GPO Sales Program, U.S. Nuclear Regulatory Commission, Washington, DC 20555

3. The National Technical Information Service, Springfield, VA 22161

Although the listing that follows represents the majority of documents cited in NAC publications, it is not intended to be exhaustive.

Referenced documents available for inspection and copying for a fee from the NRC Public Document Room include NRC correspondence and ir.ternal NRC memoranda; NAC Office of Inspection and Enforcement bulletins, circulars, information notices, inspection and investigation notices; Licensee Event Reports; vendor reports and correspondence; Commission papers; and applicant and licensee documents and correspondence.

The following documents in the NUREG series are available for purchase from the NRC/GPO Sales Program: formal NRC staff and contractor reports, NRC-sponsored conference proceedings, and NRC booklets and brochures. Also available are Regulatory Guides, NRC regulations in the Code of Federal Regulations, and Nuclear Regulatory Commission /ssuances.

Documents available from the National Technical Information Service include NUREG series reports and technical reports prepared by other federal agencies and reports prepared by the Atomic Energy Commission, forerunner agency to the Nuclear Regulatory Commission.

Documents available from public and special technical libraries include all open literature items, such as books, journal and periodical articles, and transactions. Federal Register notices, federal and state legislation, and congressional reports can usually be obtained from these libraries.

Documents such as theses, dissertations, foreign reports and translations, and non-NRC conference proceedings are available for purchase trom the organization spensoring the publication cited.

Single copies of NRC draft reports are available free upon written request to the Division of Technical Information and Document Control, U.S. Nuclear Regulatory Commission, Washington, DC 20555.

Copies of industry codes and standards used in a substantive manner in the NRC regulatory process are maintained at the NRC Library, 7920 Norfolk Avenue, Bethesda, Maryland, and are available there for reference use by the public. Codes and standards are usually copyrighted and may be purchased from the originating organization or, if they are American National Standards, from the American National Standards institute, 1430 Broadway, New York, NY 10018. 
NUREG/CR-3254

PNL-4683

$\mathrm{RH}$

\section{Licensee Programs for \\ Maintaining Occupational \\ Exposure to Radiation \\ As Low As Is Reasonably Achievable}

Manuscript Completed: March 1983

Date Published: June 1983

Prepared by

L. H. Munson

Pacific Northwest Laboratory

Richland, WA 99352

\section{Prepared for}

Division of Facility Operations

Office of Nuclear Regulatory Research

U.S. Nuclear Regulatory Commission

Washington, D.C. 20555

NRC FIN B2427 


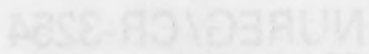

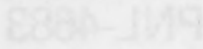 \\ Hif}

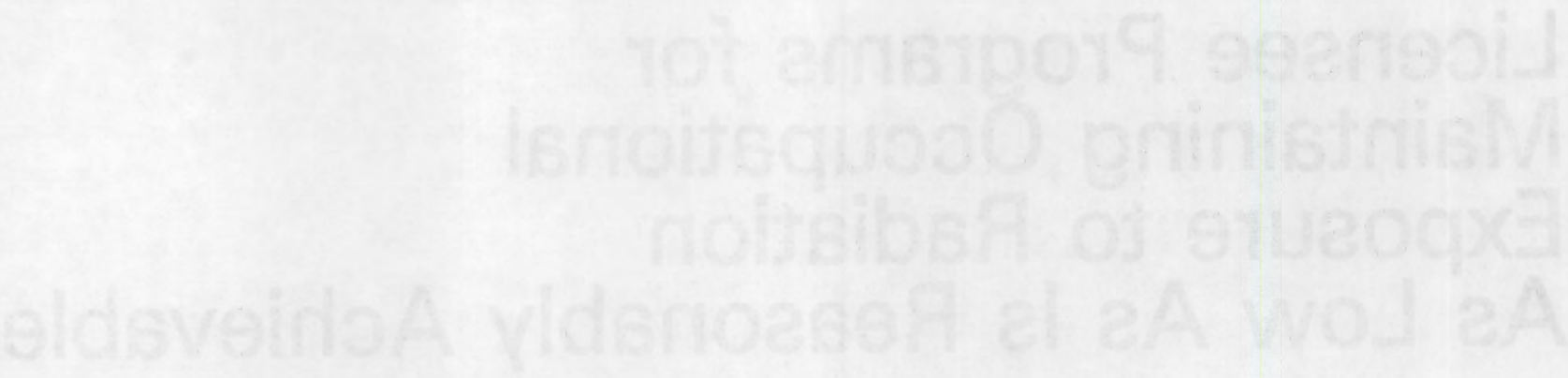

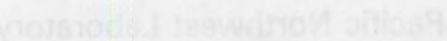

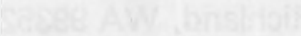

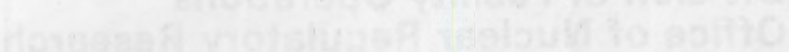

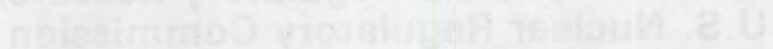

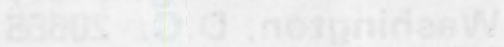

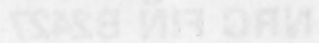




\section{ABSTRACT}

This report defines the concept of maintaining occupational exposures to radiation as low as is reasonably achievable (ALARA) and describes the elements necessary for specific Iicensees to implement, operate, and evaluate an effective ALARA program. Examples of costeffectiveness analysis and optimization are provided. The rationale for providing more detailed guidance to specific licensees stems from the current recommendations provided by the International Commission on Radiological Protection, as well as from the increased regulatory emphasis on maintaining occupational exposures ALARA. The objective of this work is to provide the Nuclear Regulatory Commission with a basis for updating Regulatory Guide 8.10. 



\section{CONTENTS}

ABSTRACT ...............................

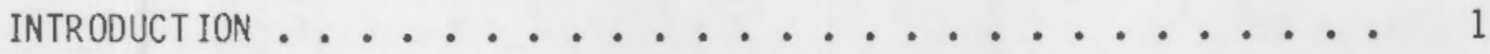

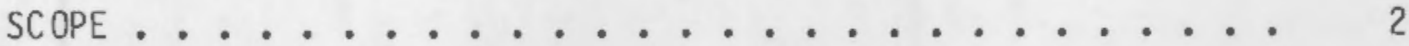

PHILOSOPHY ............... 2

ELEMENTS ESSENT IAL TO AN ALARA PROGRAM . . . . . . . . . . 4

STATEMENT OF POLICY .................... 5

MANAGEMENT SYSTEM .............. 5

ORGAN IZAT ION RESPONS IB IL ITY AND APPROVAL PROCESS $\ldots . . \cdots$

TRA IN ING . . . . . . . . . . . . 7

FAC IL ITY, PROCESS, AND EQU IPMENT DES IGN $\ldots . . . . . . .10$

Initial Design ............. 11

Design Modification ................ 12

PROCEDURE DEVELOPMENT .......................... 12

Routine Operations ............... 13

Nonroutine Operations .............. 14

Radiation Protection .............. 15

PLANNING PRIOR TO PERFORMING WORK $\ldots . \cdots 16$

OPT IMIZATION . . . . . . . . . . . 17

PROGRAM EVALUATION ......................... 25

Goal Establishment ............... 26

Measurement ................... 27

AUD IT ING THE ALARA PROGRAM . . . . . . . . . 29

REFERENCES ................................ 31

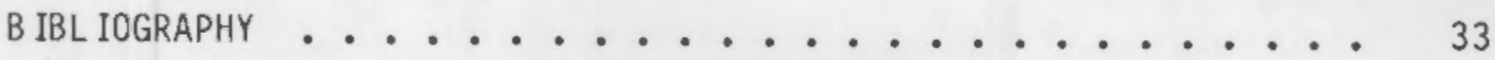


20991728?

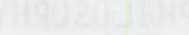

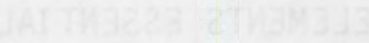

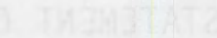

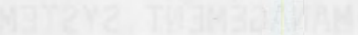

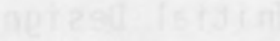

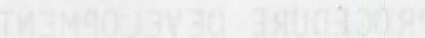

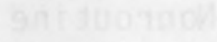

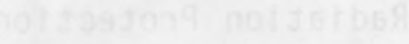

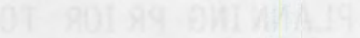

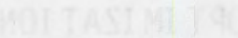

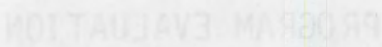

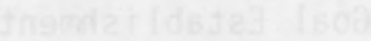

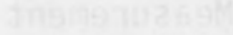

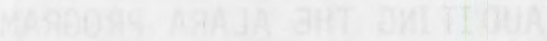

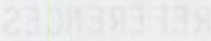

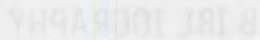




\title{
LICENSEE PROGRAMS FOR MA INTA IN ING OCCUPATIONAL EXPOSURES
}

\author{
TO RAD IAT ION AS LOW AS IS REASONABLY ACH IEVABLE
}

\section{$\underline{\text { INTRODUCTION }}$}

The principle of maintaining radiation exposure as low as practicable has long been the goal of radiation protection programs. The first regulatory requirements were introduced in Title 10 of the Code of Federal Regulations, Part 20, in January 1971. Upon

recommendation by the Federal Radiation Council and approval by the President on December 3,1970, wording was added charging licensees to "make every reasonable effort to maintain radiation exposures and releases of radioactive materials in effluents to unrestricted areas as far below limits specified in this part as practicable. The term 'as far below limits specified in this part as practicable' means as low as is practicably achievable taking into account the state of technology and the economics of improvement in relation to benefit to the public health and safety and in relation to the utilization of atomic energy in the public interest."

In the 1976 revision of 10 CFR Part 20, the term was changed to "as low as is reasonably achievable" (ALARA) and the definition changed to "... and the economics of improvements in relation to benefits to the public health and safety, and other societal and socioeconomic considerations,..."

This regulatory basis evolved from recommendations of the National Counc il on Radiation Protection and Measurements (NCRP) and the International Commission on Radiological Protection (ICRP) who first stated the basic principle as early as 1954 (NCRP 1954, p.2). Subsequent guidance has continued to expand the concept and provide more definitive criteria for determining detriment and benefit in assessing radiation exposure usage.

The most recent guidance from the ICRP (1977) further emphasizes the need for maintaining radiation exposures ALARA. The ICRP recommends a system of dose limitation, the main features of which are:

1. No practice shall be adopted unless its introduction produces a positive net benefit.

2. All exposures shall be kept as low as reasonably achievable, economic and social factors being taken into account.

3. The dose equivalent to individuals shall not exceed the limits recommended for the appropriate circumstances. 
To facilitate implementing the dose limitation system, the ICRP recommends using weighting factors to equate the detriment from irradiation of individual tissues to the detriment when the whole body is irradiated uniformly. Using these factors gives a single value for radiation dose, called radiation dose equivalent, and allows the addition of internal and external doses. This differs from current practice, in which an organ dose is related to an organ dose limit and whole body dose (normally external exposure) is related to a whole body penetrating dose limit. In addition, the ICRP introduced a process of optimization. The ICRP stated that ideally, optimization should use cost-benefit analysis to determine acceptability of a proposed operation or practice. In most practical applications, the optimization process would be used to evaluate a change in the net benefit in requiring that an activity be performed at one level of dose rather than another. The analysis would then become a differential cost-benefit analysis. Applying this analysis to a given practice, the optimization condition is fulfilled when the increase in the cost of protection per unit dose equivalent balances the reduction of detriment per unit dose equivalent.

Many of the factors that should be considered in cost-benefit analyses may be variable and, perhaps, not quantifiable. However, with all the limitations, they provide possible quantitative inputs to the decision-making process.

Cost-benefit analysis is not the only tool to be used in the optimization process and cannot be substituted for sound professional judgment. Those responsible for radiation protection in daily operations may need to rely on intuitive rather than quantitative evaluations in optimizing radiation exposure use.

SCOPE

The U.S. Nuclear Regulatory Commission (NRC) has issued Regulatory Guide 8.10, "Operating Philosophy for Maintaining Occupational Radiation Exposures As Low As Is Reasonably Achievable", which discusses the philosphy of ALARA and provides general guidance on implementing an ALARA program. Increased emphasis on maintaining radiation exposures as low as is reasonably achievable and the current recommendations of the ICRP have made it desirable for the NRC to provide more detailed guidance for all specific licensees. The objective of this work is to provide a basis for updating Regulatory Guide 8.10. This document will define the ALARA concept and describe the elements necessary for an effective ALARA program.

\section{PHILOSOPHY}

The ALARA philosophy, as it applies to personnel radiation exposure, has been a basic tenet of health physics for over 25 years (NCRP 1954). Maintaining radiation exposure as far below the limits as practical or reasonable is an important function of any effective radiation protection program. The ALARA concept is a part of the 
radiation protection effort, not a separate entity. While certain activities may be identified and conducted as an ALARA action, these same activities should be part of a normal, comprehensive health physics program. Consequently, defining and emphasizing ALARA elements to assure appropriate consideration is predicated on a strong and effective health physics program.

The basic ALARA objective is to ensure that radiation exposures to workers and to the public are kept to the lowest levels commensurate with sound economics and operating practices. Current thinking is that any radiation exposure, no matter how small, may carry with it some degree of detriment or risk for causing certain types of injury. Al though the level of risk associated with radiation exposure limits is very small, it is prudent to keep exposure, thus risk, as low as is reasonably achievable and to assure that this risk is assumed only if comparable benefit is achieved. In other words, it is always appropriate to seek cost-effective ways to reduce exposure or to do more work with less dose received.

As with all other health physics functions, to accomplish ALARA requires a unified effort. In addition to the radiation protection specialist or organization, all others who effect the management, design or modification, operation, maintenance or resources of a facility in which radiation exposure is received must be involved in the development and implementation of the radiation protection and ALARA program.

Achieving a successful ALARA program requires that 1 icensee management at all levels be cognizant of and committed to the ALARA principles and goals. Only through a sincere management commitment and the transfer of that commitment to each employee can the ALARA concept be effectively realized. Licensees' radiation protection organizations are fundamental in carrying out the radiological and environmenta? protection functions. Included in these primary functions are the measurement and control of radiation exposures, which form the basis for ALARA evaluation.

Certain elements are essential to an effective ALARA program. The degree of effort by a particular licensee may vary depending upon the size of a licensee's operation, the kinds of activities performed, the extent of the hazards involved, and the resources available. However, each element must be provided to implement an ALARA program. These elements are described in detail in the next section. 


\section{ELEMENTS ESSENT IAL TO AN ALARA PROGRAM}

A health physics program should identify and describe those elements that will be used in the ALARA program and its

implementation. While each of these elements may also be used in carrying out the normal radiation protection functions, their

relationship to and application in implementing the ALARA concept should be defined and details provided. The elements of an ALARA program should include:

1. statement of pol icy

2. management system for policy implementation

3. organization responsibility and approval process

4. training program

5. strategy for incorporating ALARA considerations in the initial design and modification of facilities, processes and equipment

6. strategy for factoring ALARA into procedure development and reviews: general, routine and nonroutine operations, and health physics

7. provisions for planning prior to performing work

8. optimization process

9. system for analyzing dose trends, setting dose goals, measuring goal accomplishment, and analyzing performance

10. in-house audit system to evaluate ALARA program effectiveness and correct deficiencies.

Formal identification of ALARA program elements is essential to assure that all facets of the program are understood and implemented and that responsibilities, goals, and methodology for implementation are clearly specified.

A clear definition of the program must be available to all levels of a licensee's staff. The documentation should demonstrate the importance that management places on the ALARA principle, the level of attention that it will receive, and the methods that will be used to establish ALARA program goals, measure them and evaluate performance to meet those goals. Further, the formal documentation should emphasize not only that the highest levels of management are committed to and support the ALARA program, but that the efforts of each individual are needed and expected for optimal performance. Such a clear definition of 
the ALARA program will enable each individual worker to more easily understand the significance of the program and the value of his participation.

\section{STATEMENT OF POL.ICY}

A statement of the management policy and commitment to ALARA should be developed, issued, and available. This policy statement should ensure that all personnel clearly understand that implementation of the ALARA concept is the desire and goal of management, is the responsibility of all individuals within the facility (regardless of their specific delegated responsibilities), and that all personnel will be evaluated and held accountable for performance according to the ALARA program precepts.

The policy statement should describe the intent of the program, the importance of its implementation and general responsibilities, the program goals and how specific milestones for their achievement are to be established, and the management system for program implementation, maintenance, and evaluation.

\section{MANAGEMENT SYSTEM}

The management system to implement and maintain the ALARA program should be defined. The management system definition should specify in detail those actions that will be taken to assure effective exposure usage. It should provide for adequate resources for the program including both personnel and equipment. The system should specify the documentation required for the program. It should al so describe the communications network from management to the staff and the feedback system to management to promote full staff participation.

While the health physics organization and responsibility assignments will normally include overseeing the ALARA program, responsibilities and organizational reporting chains specifically pertinent to the ALARA program should be defined. The system should assure that those responsible for coordinating the ALARA program are basically independent from operational pressures. The management system may provide for an independent committee, reporting directly to senior management, to review the activities of the program. Or it may provide this overview and coordination activity through a single individual such as the health physics manager or a specified ALARA coordinator. In other instances, this function may be included as part of the duties of a radiation protection committee. The functions of this committee or coordinator are to assure that the ALARA elements are included in all phases of operation concerning radiation exposure and radioactive materials, to evaluate the effectiveness of ALARA actions, and to provide recommendations for improvement. 
Whatever the mechanism, the results of the reviews and recommendations of the responsible person or committee should be reported to the senior management with overall responsibility for the operation, as well as to the staff. The management system should define the methods by which the effectiveness of the program is evaluated, the criteria for evaluation and the actions to be taken by management to assure active participation by the staff and achievement of ALARA goals.

Any organizational structure may be made effective in implementing the health physics and ALARA program with active management support and attention. However, care must be exercised to assure that structure's independence from the pressures of production or other requirements.

Those responsible for coordinating the ALARA program must have a direct line of communication to senior level management. A direct reporting link to senior management is generally most effective, but other organizational structures may be used if direct communication is assured. For example, an ALARA coordinator may have functions and responsibilities in areas other than ALARA that would require his assignment organizationally to another level of management. In these cases a direct line of communication (dotted line structure) should be provided to senior management to assure open transfer of information without bypassing traditional organizational lines.

It must be made clear to all that, even though one individual or group is responsible for coordinating the efforts, each individual is responsible for understanding and carrying out the ALARA program. It is especially important that first-line supervision of all radiation exposure user components recognize their responsibility and understand and practice the ALARA concepts.

ORGAN IZAT ION RESPONS IB IL ITY AND APPROVAL PROCESS

Those assigned responsibility for coordinating the ALARA program must establish close cooperation with radiation exposure user components and components whose duties affect the management, design, training, operation, and maintenance of the facility. In addition, a formal approval process should be established to assure that ALARA el ements are considered and included, if appropriate, in:

- design and modification of the facility and/or processes

- training programs for personnel

- operation, maintenance, and health physics procedures

- resource allocation. 
The ALARA organization should be given the authority to review, recommend, and approve, as meeting ALARA requirements, the following:

1. initial designs developed for the facility and/or processes and for modification to them

2. operating procedures that involve or affect radiation exposure

3. maintenance procedures for work in radiation or contamination areas and with radiation-generating equipment

4. health physics procedures

5. training programs

6. special or unique work activities or work plans.

Each of these areas is especially important to effective implementation of exposure reduction actions. While exposure reduction to ALARA is each individual's responsibility, the ALARA organization must review these activities to assure that exposure reduction has been specifically considered and appropriate techniques implemented.

TRA IN ING

Effective and successful implementation of an ALARA program requires knowledge and understanding of the ALARA concept. Thus, training of personnel in ALARA and radiation protection principles is probably the single most important element in an ALARA program.

Al1 personnel whose duties require 1 ) working with radioactive material, 2) entering radiation areas, 3) directing the activities of others who work with radioactive materials or enter radiation zones, and 4) operating, maintaining, designing, and modifying facilities and equipment using radioactive materials or producing radiation, should be familiar with the ALARA policy and program and be trained in radiation protection and ALARA practices.

The training provided should be appropriate to the function and/or responsibility of the recipient. Training should be provided for the following groups:

- administrative staff

- general employees

- visitors and temporary staff

- management

- operation and maintenance staff 
- design engineering

- health physics staff.

The training necessary for personnel may vary widely but all staff should be knowledgeable of the emergency signals and appropriate response actions.

General employees who may enter a radiation area should be provided specific training in ALARA in addition to any other necessary topics such as industrial safety and radiation protection. The ALARA-specific training should include:

- statement of ALARA policy

- explanation of the ALARA concept

- instruction on individual responsibility for maintaining radiation exposure ALARA

- emphasis of management commitment and participation

- description of management system for ALARA implementation, goal development and measurement, and actions to assure ALARA implementation.

Visitors to a facility, if they will be entering radiation areas, should receive the same training as necessary for general employees unless they will be continuously escorted by trained personnel. The training necessary for temporary staff will depend upon the functions they will be performing in the licensee's operation. As a minimum, temporary staff who will be entering radiation areas unescorted should have the same training as necessary for general employees. In addition, temporary staff members assigned to specific functions, such as design engineering or health physics, should receive training in ALARA as recommended for 1 icensee staff in those functions.

Al1 management staff, because of their influence in the performance of a facility's operation, are especially important to the effective implementation and maintenance of an ALARA program. Because of this importance, specialized training should be given to provide understanding of ALARA concepts and their significance to facility operation. Recommended topics are:

- general nontechnical review of radiation hazards and radiation protection policies

- importance and overall justification of the ALARA program 
- specific requirements to ensure ALARA policies are being implemented at all employee levels

- necessity of relying on the technical services and advice of the radiation protection staff

- effects of each organizational component's activities on the overall achievement of ALARA program goals

- responsibility for providing all workers with awareness of specific safe job practices and ALARA applications

- procedures for evaluating ALARA performance.

The operation and maintenance staff generally receive most of the radiation exposure used in a facility. Consequently, they have frequent opportunity to recognize first-hand ways to reduce radiation exposure. Training programs for operation and maintenance personnel should ir.clude :

- the basic ALARA concept and its purpose

- importance and justification of the program

- upper management's commitment to ALARA and level of participation

- necessity of relying on the technical services and advice of the radiation protection staff

- specific requirements to ensure ALARA policy implementation

- responsibilities of managers, supervisors and individuals for ALARA program implementation

- examples of ALARA techniques such as planning and briefings, prework dry-runs, use of mockups, and decontamination.

Personnel involved in the design of facilities and processes should be trained in radiological design. General engineering or similar education may not be adequate to assure recognition of radiological concerns. In addition, design personnel should be trained in ALARA principles. This training should include:

- the basic ALARA concept and its purpose

- importance and overall justification of the ALARA program

- upper management's commitment to ALARA

- specific techniques for the optimization process 
- techniques and practices in designing for minimum radiation exposure

- radiation exposure considerations in selection and placement of equipment (reliability, maintenance, access)

- radiation exposure considerations in building layout, radiation zone control, ventilation control, and operation and maintenance.

A strong health physics organization is fundamental to radiation protection and effective exposure optimization. Assisting in accomplishing radiation work with minimum exposure and maintaining personnel exposure as low as practicable has long been part of health physics. However, additional ALARA training should be provided to emphasize its importance. The degree of training provided will vary with radiation protection staff members' level of experience, education, and assigned work functions. The training should include:

- importance and justification of the ALARA program

- the degree of management commitment and participation in ALARA implementation

- ALARA design and optimization techniques

- responsibilities for recognizing and practicing radiation exposure optimization techniques

- the management system for ALARA program implementation, goal development and measurement, and performance evaluation

- general exposure reduction techniques and site-specific practices.

FAC IL ITY, PROCESS, AND EQUIPMENT DES IGN

The design of facilities, processes, and equipment necessary for the performance of work with radioactive materials or with radiationgenerating machines provides one of the first opportunities for ensuring radiation exposures as low as reasonably achievable. The design process requires close coordination among many disciplines to accomplish the major objective of providing a usable facility, process or piece of equipment and to incorporate radiation protection and ALARA objectives as well. The process requires the input of administrative personnel to establish the need and resources available, operations personnel to define operational needs, architect-engineers, ventilation design and many other engineering disciplines and, when radioactive materials or radiation-generating equipment is involved, health physicists to assure that radiation protection requirements are met and ALARA concepts are incorporated. 
The design will be determined not only by the functional considerations of the facility, process, or equipment, but also by radiological factors. These factors include the type and quantity of radioactive material; the type, size and purpose of radiation-generating equipment; and the magnitude of the potential for internal and external radiation exposures to workers and to the public.

Initial Design

Because of the broad spectrum of personnel involved, it is particularly important at the initial design phase that all involved understand the ALARA concept and management's commitment to it. Even though some disciplines may not be direct employees of the user organization, the user organization is responsible for assuring that exposure reduction criteria are included in the design. This may necessitate requiring ALARA reviews as part of the contract, or performing an ALARA design review and approval by user organization health physics and engineering staff.

The design of facilities, processes, and equipment provides an early opportunity to optimally reduce radiation exposure. Numerical guidelines for radiation doses to the public are provided in Title 10 of the Code of Federal Regulations. Methods for calculating doses to the public from facility releases and estimating occupational radiation doses in the design stage for reactors are provided in Regulatory Guide 8.19, "Occupational Radiation Dose Assessment in Light-Water Reactor Power Plants Design Stage Man-Rem Estimate," and in Regulatory Guide 1.109, "Calculation of Annual Doses to Man from Routine Releases of Reactor Effluents for the Purpose of Evaluating Compliance with $10 \mathrm{CFR}$ Part 50, Appendix I." While these are for reactors only, they may provide guidance for other facilities.

The general design criterion for occupational radiation exposure is to design such that personnel exposures will be as low as reasonably achievable. Dose goals should be established and detailed attention given to each potentially significant dose-causing activity. Quantitative assessment should be performed to ensure that costeffective techniques of dose reduction are considered and that none is overlooked. The quantitative method for deciding what is reasonably achievable in dose reduction ordinarily uses a cost-benefit analysis process. A basic assumption of a linear, nonthreshold dose-response relationship for stochastic radiation effects such as cancer and hereditary harm leads to the conclusion that any quantity of radiation exposure, no matter how small, carries with it some expectation of harm or detriment.

The evaluation of this reduction of expectation of harm due to the reduction in collective radiation dose from a specific design feature versus the cost, both in construction and operation, of incorporating the feature provides the basis for the optimization process. This process is discussed in depth under Optimization. 
Design Modification

Modification of facilities, processes, and equipment al so provides an opportunity to incorporate ALARA concepts by engineering. Changes to facilities, processes, and equipment present both advantages and disadvantages for ALARA. On the positive side, facility-specific historical data on exposure levels and use, reliability, and maintenance requirements of equipment should be available for evaluation. Each of these factors may be used to determine the changes most effective in achieving ALARA. However, in modification of existing facilities, processes, and equipment, certain limitations are frequently encountered. The available space, basic layout and structural features may al ready be established. The primary processes may be determined and various procedures and flow paths may not be readily changed. The equipment specifications, spacing and type may be set and changes to reduce exposure potential not possible. Although these limitations may exist, design changes should be reviewed to consider and incorporate, where possible, exposure-saving features. Depending on the extent of the modifications, the ALARA review may involve quantitative optimization calculations and in-depth evaluation of options available. In other cases, the review may lead to an intuitive decision based on professional judgment of the management and health physics staff. However accomplished, consideration of means to effectively reduce radiation exposure should be included in modifications to facilities, processes, and equipment.

The management system should assure that ALARA concepts are factored into design and modifications. Those operations in which radiation exposures are high, individually or collectively, or that have high hazard potential may require a formal ALARA review system with checklists, specific procedures and authorizing signatures. In other operations with minimal hazard potential, a simple narrative report of the factors considered, actions taken and rationales for the decisions made may be adequate. Documentation of these reviews, simple or indepth, is advisable to provide historical records for management audit and for reference to verify that decisions made have been implemented and were effective.

PROCEDURE DEVELOPMENT

Written procedures are necessary tools to ensure that specific guidance is provided for tasks that:

1. must be done in a precise way

2. must be done in the same way repetitively

3. are complex and involved in detail

4. require specific or unique instructions 
5. must be especially controlled.

Procedures developed for activities involving work with radioactive materials or in radiation areas usually fall into one or more of these categories. Procedures and the procedure development process should be used to ensure that ALARA considerations are included in work

activities.

\section{Routine Operations}

The procedures issued for routine operational activities should be reviewed for potential exposure reduction opportunities. Procedures should be reviewed and approved by those responsible for coordinating the ALARA program prior to issue, when significant modifications occur, and periodically during use. Procedures should be reviewed for:

1. validity of the procedure for the work

2. clarity of the procedure in describing what to do and how to do it

3. the impact of each step on radiation exposure, both internal and external

4. radiological considerations

a. shielding

b. remote operation

c. distance

d. specialized tools

e. protective equipment

f. manpower requirements

9. airborne radioactivity potential

h. exposure rates

i. exposure times

j. alternatives or contingencies

5. the impact of performing the procedure on other activities and/or locations.

The basic purpose of analyzing the procedures is to identify the actions that affect the radiation exposure of personnel and to assess those actions to ensure that exposures have been reduced to ALARA. A 
care must be taken to prevent the review from becoming a mechanical process rather than a considered assessment.

Nonroutine Operations

Nonroutine or special procedures may require particularly careful review. The ALARA program should establish criteria specifying when procedure reviews are required and the review and approval process. A graduated system requiring increasingly rigorous reviews and higher levels of authorization based upon hazard potential may be warranted. Hazard potential may be categorized using radiological parameters such as estimated cumulative dose to be received, dose rates anticipated, quantity of radioactive material, or airborne radioactivity expected. Activities for which nonroutine or special procedures are needed may be a one-time or infrequently performed activity, a high-hazard potential activity or an especially complex activity. In each case an in-depth ALARA review should be conducted to assess the step-by-step actions to ensure that exposure reduction techniques have been considered. Because conduct of nonroutine activities may not be familiar to personnel, additional requirements may need to be included in procedures for prework briefing, training, dry-run practice, and additional radiological controls. The procedure development process should ensure that special procedures receive an in-depth review and that the results of the review are documented for use in planning activities and ALARA program evaluation.

In addition to operational procedures, a system of special or radiation work procedures or permits (SWP or RWP) should be used to provide radiological information and controls for work in radiation areas or with radioactive materials. Typical RWPs or SWPs contain information on radiation and contamination levels expected, protective equipment needed, dosimetry required, radiological surveillance needed, and special precautions to be followed. These procedures may be used to record information of interest in 1) the identification and analysis of activities in which radiation exposure is received, 2) trend analysis, and 3) evaluation of the effectiveness of ALARA techniques. This information should include:

- designation of services to be performed on specific components, equipment, or systems

- number and identification of personnel working on the task

- measured or anticipated radiation levels, airborne radioactive material concentrations, and contamination levels

- monitoring requirements such as continuous air monitoring or sampling 
- estimated exposure time required to complete the tasks and the estimated doses anticipated

- special instructions and equipment to minimize the exposure of personnel to radiation and contamination

- protective clothing and equipment requirements

- authorization to perforn the tasks

- exposure time, doses, and other information obtained during the operation.

Radiation Protection

Procedures should be developed to provide guidance for activities specifically associated with radiation protection and ALARA. These procedures should be carefully evaluated to ensure that appropriate radiation exposure control techniques are included.

Procedures for control of radiation protection activities may be overlooked in exposure reduction efforts because of the functional expertise of the personnel to whom they are directed. However, radiation exposures of the radiation protection personnel may constitute a significant portion of the total exposure received from an activity and may provide opportunities for exposure reduction to ALARA. All procedures, the performance of which may involve receiving radiation exposure, should be evaluated for ALARA. Radiation protection activities that should be evaluated include, but are not limited to:

1. routine surveys to determine radiation, contamination, and airborne radioactivity status

2. surveys in high dose rate areas

3. any activity for which continuous radiological surveillance is required

4. calibration of radiation protection instruments

5. personnel decontamination

6. sample collection and evaluation.

In some operations that use an SWP - RWP system for procedural control of work in radiation areas, the SWP or RWP for the radiation protection activities may be a general permit authorizing entry with few, if any, guidelines provided. The specific activity authorized by the SWP or RWP should be identified, an ALARA review performed, and guidance provided in the procedure, if warranted, to ensure maintaining radiation exposures ALARA. Personnel exposure to perform surveys of 
radiation areas may be minimized by using area radiation monitor readings and data from remote readouts of continuous air monitors.

Activities conducted by the radiation protection staff may have particular significance in maintaining radiation exposures to all personnel ALARA. For example, the timely and accurate posting of radiation, contamination, and airborne radioactivity areas and the evaluation, selection, and recommendations made for use of protective equipment may minimize inadvertent external and internal exposures.

Procedures should provide guidance to radiation protection personnel on potential situations and techniques for maintaining radiation exposures to personnel ALARA. Radiation protection and ALARA procedures should be reviewed and approved by those responsible for radiation protection and for coordinating the ALARA program, as well as by a qualified reviewer independent of the radiation protection and ALARA organization.

PLANN ING PR IOR TO PERFORMING WORK

The effective use of planning before the job will provide one of the best opportunities to reduce personnel exposure. Prior planning allows time for determining the task to be accomplished, how it is best done, the resources necessary (including equipment, manpower and radiation exposure), the impact on surrounding activities and the impact of surrounding activities on the planned task. In addition, prior planning allows assessment of the training and skills necessary to do the work and, perhaps, the opportunity to use mockups to familiarize workers with the operation and practice sessions to sharpen skills, improve techniques and identify weaknesses in procedures.

Each of these facets of the review can reduce the time required to do a task, increase the efficiency of the work force and assure that unplanned delays or disturbances will be minimized. These effects, in turn, will ensure that any radiation exposure incurred is necessary to accomplish the work. This is ALARA.

Planning of work activities is particularly important in operations with high hazard potential, high radiation dose rates or potential airborne radionuclide concentrations, unusual or unique tasks, special maintenance tasks, recovery from accidents, or tasks with high cumulative exposure use. A system to assure planning for activities such as these should be included in the management system for ALARA implementation.

Depending on the potential hazard, formal planning procedures may need to be implemented. This may require developing a pre-work plan. A list of specific items to be reviewed in the pre-work planning can be used to assure that techniques to reduce personnel exposure are included. 
The pre-work plan should be reviewed by qualified people and approved by management before starting the work. If personnel having the necessary qualifications to perform adequate health physics reviews are not available within the licensee's operation, it may be necessary to arrange for these reviews, or qualified personnel to perform them, from outside sources.

The planning and review process should be documented and records maintained for review by those responsible for coordinating the ALARA program and by management. In addition, documentation may be beneficial for tracking the program and as a basis for improving the planning process.

\section{OPT IM IZAT ION}

The reduction of radiation exposure to ALARA is a philosophical concept; its actual implementation depends on the individual interpretation of "reasonably achievable". Al though the concept is not new, its application in licensee operations has been a subjective, intuitive process varying in effect depending upon the interests of management and the strength of the radiation protection organization. The cost of achieving a level of protection is a factor in all operations. However, the cost of maintaining radiation exposures at or below the regulatory 1 imits is not only good practice and legal protection, but a legal obligation. The magnitude of the resource commitment required to meet the 1 imits is irrelevant if activities are to continue. The reduction of radiation exposure to as far below the limits as reasonably achievable is the domain of ALARA.

The ICRP (1977) reemphasized the application of the ALARA concept and introduced an optimization process to assist in accomplishing the ALARA principle. The purpose of the process is to determine whether or not an activity "is being performed at a sufficiently low level of collective dose equivalent so that any further reduction in dose would not justify the incremental cost required to accomplish it." The quantitative methodology used in making this determination is an ideal approach and licensees should be encouraged to apply it.

To use optimization quantitatively first requires establishing a common basis for comparing the cost of reducing radiation exposure to the benefit of having done so. Once this comparative baseline is established, calculations can be performed to determine if the benefit gained (exposure reduction) is equal to or greater than the cost of implementing the dose reduction practice, or, as shown mathematically,

$$
\text { Benefit ? Cost }
$$

Thus, if the benefit equals or exceeds the cost, then the practice being evaluated should be implemented. 
The NRC has specified a numerical value of $\$ 1,000$ per total body person-rem and $\$ 1,000$ per person-thyroid-rem to be used in cost-benefit analyses for exposure reduction to the public (10 CFR 50, Appendix I). Other values ranging from $\$ 30$ per person-rem to $\$ 60,000$ per person-rem may be found in the literature (Kathren et al. 1980; NRPB 1982; Voilleque and Pavlick 1982).

Numerical values of person-rem for occupational exposure have not been established. Factors in addition to those considered for personrem values for public exposure must be assessed. This assessment should include level of radiation dose, individual choice, dose distribution, and other political and social concerns.

Acceptable individual occupational doses may be higher by factors of hundreds or thousands than individual public doses. The acceptability of a higher risk to a limited group may be different than that of a much lower risk to a large population. The acceptability is further influenced by the recognition that a radiation worker voluntarily receives radiation exposure as part of his employment while public exposures, on an individual basis at least, are nonvoluntary. In addition, the dose distribution to the public is basically random as to physical parameters, and, normally, individual dose assessment is not made. Conversely, occupational exposures are to workers who must meet defined criteria and are individually monitored and controlled for radiation dose received. Other political and social factors, such as national needs, alternatives, and public perception, also affect determination of person-rem values for occupational exposure.

Until a more definitive value is established, the same value is used for both occupational and public exposure reduction so that a quantitative evaluation can be made on a case-by-case basis of the costeffectiveness of specific ALARA actions. In the day-to-day operations many actions taken to reduce radiation exposure may be evaluated by intuitive judgment. However, the use of quantitative optimization should be encouraged as a definitive tool for the decision making process.

A simplistic approach to cost-effectiveness analysis may use a formulation such as

$$
\begin{gathered}
\text { Benefit } \geq \text { Cost } \\
B+U \geq M+L+N+0+E+R
\end{gathered}
$$

where $B=$ dose reduction in person-rem achievable if the practice is implemented multiplied by $\$ 1,000$

$U=$ intangible benefits multiplied by an estimated value for each benefit. These intangible benefits could include: 
- improved public relations due to lower exposure use

- increased flexibility in use of personnel resources

- other undefined benefits.

$M=$ dollar cost of materials required to implement the practice

$L=$ dollar cost of labor

$\mathrm{N}=$ dollar cost of maintenance of the practice

$0=$ dollar cost of operation

$E$ = radiation exposure in person-rem necessary to install and maintain the practice multiplied by $\$ 1,000$

$R=$ intangible costs of the practice such as

- restriction in access to or use of space

- adverse effects on ancillary operations

- other undefined costs.

The ALARA concept is depicted in Figure 1. The straight line (A) in Figure 1 illustrates the assumption that radiation exposure, no matter how small, carries with it some risk of detrimental effects and that the risk is proportional to dose at all levels of dose (linear hypothesis). The slope of Line A reflects the cost assigned to personrem.

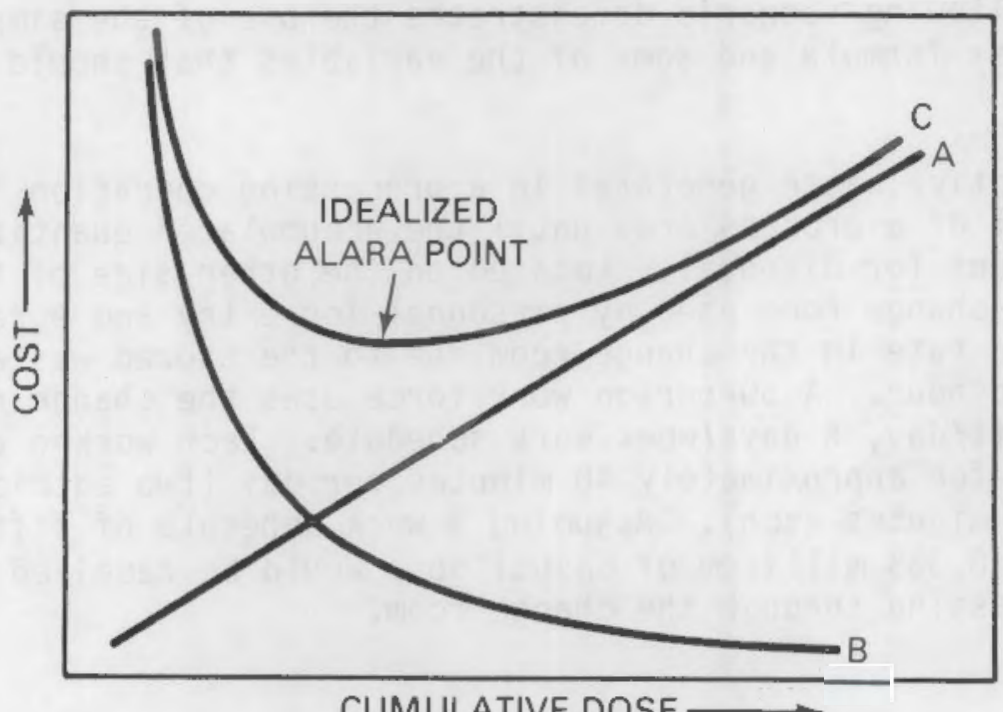

FIGURE 1. The ALARA concept 
Line $B$ represents dose reduction costs. The curve of the 1 ine 111 ustrates that dose reduction costs are variable. Quite often the larger dose reductions are achieved at relatively low cost while each additional increment of dose reduction becomes more and more costly.

Line $C$ is a summation of 1 ines $A$ and $B$. If real istic values are used for both the cost of radiation dose incurred and the cost of dose reduction, the minimum point of Line $C$ is the idealized ALARA point or the point at which the costs of achieving an additional unit of dose reduction are exactly balanced by the acceptable cost per unit dose incurred.

It should be recognized that the idealized ALARA point on Line $C$ is fixed by the value given to the person-rem and the cost of implementing the dose reduction practice. The optimization process can be used to approximate that point for each dose reduction practice being considered. However, the slope of Line A may change depending upon the group being exposed (public or occupational) and the level of exposure being considered. Consequently, the curve of Line $C$ (and the idealized ALARA point) will change. Similarly, a change in the cost of implementing a dose reduction practice (Line B) will change the curve of Line $C$ (and the idealized ALARA point). This means that, even if the optimization process has been completed for a particular dose reduction practice (e.g., installation of a shield wall), if a less expensive method of providing the same dose reduction is found, the optimization process should be repeated for reevaluation.

The curve of Line $B$, the cost of implementing a dose reduction practice, is the variable most influenced by the experience and judgment of the health physics and ALARA professionals.

The following scenario demonstrates the use of the simplified costeffectiveness formula and some of the variables that should be considered.

Radioactive waste generated in a processing operation is stored along a wall of a process area until the accumulated quantity warrants a waste shipment for disposal. Located on the other side of the storage wall is the change room used by personnel for entry and egress. The average dose rate in the change room due to the stored waste is 1 millirem per hour. A 50-person work force uses the change room each day for a 1 shift/day, 5 days/week work schedule. Each worker occupies the change room for approximately 40 minutes per day (two entries and two exits at 10 minutes each). Assuming a work schedule of fifty weeks per year, about 8,333 millirem of casual dose would be received by plant personnel passing through the change room. 
In this scenario, efforts to reduce the cumulative dose to personnel from this source could save up to 8.3 person-rem per year if the average dose rate were lowered to background. The dose reduction could be 24.9 person-rem per year for a 3 shift/day schedule and 36.4 person-rem per year for a 3 shift/7 day schedule. In addition, if individual doses are near the regulatory limits or are restricting the work assignments of some workers, the dose reduction would permit productive use of the dose saved. This dose reduction could be equivalent to having two to eight additional radiation workers available. Intangible benefits may include improved publ ic image to employees, senior management, and regulators by demonstrating the importance of exposure optimization.

In the formula, these benefits would appear as:

$$
\begin{gathered}
B+U \geq M+L+N+0+E+R \\
8.3(\$ 1,000)+U \text { or } 8.3(\$ 1,000)+\$ 100,000^{(1)}+U^{(2) \geq} \\
M+L+N+0+E+R \\
\$ 8,300+U \text { or } \$ 108,300+U \geq M+L+N+0+E+R
\end{gathered}
$$

where (1) is the estimated annual cost of a full-time employee $x 2$ (if exposures are limiting)

(2) is the intangible benefit of improved public relations.

Moving to the right side of the equation, the dose reduction practice to be evaluated must be selected. For this example, two options are: 1) move waste storage to another location and 2) install additional shielding between the waste and the change room.

If an alternative waste storage location could be made available, the cost of preparation and maintenance of that location should be evaluated and the exposure and labor needed to transport the waste to it estimated. The transport cost could be a continuing expenditure because the waste is generated near the present storage area. In addition, the personnel exposure incurred due to increased background near the alternative area must be included.

If $i t$ is assumed that alternative locations are not feasible and that individual doses are not limiting, the calculations show that a net benefit would be realized if the exposure could be reduced to background levels at a cost of $\$ 8300$ or less per year of change room use.

Installation of a filled concrete block wall could reduce the dose by a factor of 10 (or greater) and cost about $\$ 10,000$. It is assumed that installation would require 1.0 person-rem of radiation dose due to the higher dose rates in the waste storage area. The dose to personnel to install the wall could be substantially reduced if wall construction 
were scheduled immediately after a waste disposal shipment when stored waste volume was minimal. Using the above assumption, the equation would appear as:

$$
\begin{gathered}
\$ 8300+U=M(\$ 2000)+L(\$ 8000)+N(0)+0(0)+E(1 \times \$ 1000)+R(\$ 1200)^{(1)} \\
\$ 8300 / y r+U=\$ 11,000+\$ 1200 / y r
\end{gathered}
$$

where (1) $\$ 1200 / \mathrm{yr}$ is the estimated value of the storage space $\left(200 \mathrm{ft}^{3} \mathrm{x}\right.$ $\left.\$ 6 / \mathrm{ft}^{3} / \mathrm{yr}\right)$ lost to the new wall.

Thus, if the operation is to be continued for 20 months or more on a 1 shift/day, 5 day/wk schedule, the shield wall should be installed. Expanding the work schedule would make the shield installation even more costeffective.

This example is a basic cost-effectiveness analysis and may be used to determine which method of controlling exposure should be considered first. When the selection of a dose reduction practice is made, the process of optimization may be performed. Optimization (differential cost-benefit analysis) is intended to maximize the net benefit from the practice being considered; i.e., determining the point of optimal benefit for the cost expended to achieve it. The optimization condition is fullfilled at a value, $S$, collective dose equivalent, such that the increase in the cost of protection per unit dose equivalent balances the reduction of detriment per unit dose equivalent; i.e.,

$$
\begin{aligned}
& \frac{d X}{d S}=-\frac{d Y}{d S} \text { or } \\
& \frac{d X}{d S}+\frac{d Y}{d S}=0
\end{aligned}
$$

where $x=$ cost of achieving a selected level of protection

$$
\begin{aligned}
& Y=\text { cost of the detriment involved in the operation } \\
& S=\text { collective dose equivalent. }
\end{aligned}
$$

The following example of the optimization process uses the same scenario as the cost-effectiveness analysis previously shown. In that example, it was demonstrated that installing a shield wall between the change room and the waste storage area was cost-effective. This example demonstrates how to determine the optimal thickness of the shield wall. 
The cost of detriment $(Y)$ as a function of the shield wall thickness ( $t$ ) can be written as

$$
Y(t)=\alpha H f N T e^{-\mu t}
$$

where $\alpha=$ cost assigned to a unit of radiation dose and should include all the intangible costs in the term " $U$ " of the costeffectiveness formula $=\$ 1000 /$ person-rem

$$
H=\text { existing annual dose rate }=8.76 \mathrm{rem} / \mathrm{yr}
$$
(8760 $\mathrm{hr} /$ year $\times 1 \mathrm{mrem} / \mathrm{hr}$ )

$f=$ occupancy factor of the change room $=0.0189$ (0.66 hr/8hr $\times 8 \mathrm{hr} / 24 \mathrm{hr} \times 5$ days/7 days $\times 50 \mathrm{wk} / 52 \mathrm{wk})$

$N=$ number in exposed group $=50$

$T=1$ ife of the facility $=20$ years (assumed)

$\mathrm{e}^{-\mu t}=$ exposure reduction factor

$\mu=$ effective absorption coefficient $=14 /$ meter (for concrete and $0.7 \mathrm{MeV}$ photons must include buildup factor)

$t=$ thickness of shielding in meters.

The terms HfNT are simply a measure of the radiation exposure. The term $e^{-\mu t}$ shows the dependence of the dose on the thickness of the shielding.

The cost of protection $(X)$ as a function of the shield wall thickness ( $t$ ) can be written as

$$
x(t)=x h l t+\text { whlt }
$$

where $x=$ installed cost of a filled concrete block shielding wall $=\$ 400 / \mathrm{m}^{3}$

$h=$ height of installed shielding $=3 \mathrm{~m}$

1 = length of installed shielding $=12 \mathrm{~m}$

$w=$ value of storage space occugpied by the installed shielding wall $=\$ 120 \mathrm{ft}$ or $\$ 3240 / \mathrm{m}$ over the 20 -year 1 ife of the facility. 
The exposure of 1 person-rem to install the shield wall is assumed to be independent of the wall thickness because the work would be performed on the source side of the wall and does not affect the optimization calculations.

The differential equation expressing the optimization as a function of shield thickness then becomes

$$
\frac{d Y(t)}{d t}+\frac{d X(t)}{d t}=0
$$

Differentiating and solving for $t$ gives

$$
t=\frac{-\ln \left[\frac{h l(x+w)}{\alpha H f N T \mu}\right]}{\mu}
$$

Substituting the appropriate values gives

$$
\left.t=\frac{\ln \frac{(3 \mathrm{~m})(12 \mathrm{~m})\left(\$ 400 / \mathrm{m}^{3}+\$ 3240 / \mathrm{m}^{3}\right)}{(\$ 1000 / \text { person-rem) }(8.76 \text { person-rem/yr)(0.0189)(50men })(20 \mathrm{yr})(14 / \mathrm{m})]}}{14 / \mathrm{m}}\right]
$$

$$
=0.205 \mathrm{~m}=8.07 \mathrm{in} \text {. }
$$

Thus, the optimal shielding thickness is $0.205 \mathrm{~m}$ or $8.07 \mathrm{in}$. The fact that standard concrete block dimensions are 8 in. $x 8$ in. $x 16$ in. was not relevant to the result, although formulation using incremental steps instead of a continuous function can be used.

The solution to this optimization problem can be found graphically as well by calculating the values for cost of detriment (Y), cost of protection $(X)$, and total cost (Table 1) for a series of shield thicknesses and plotting them. Figure 2 shows the resulting curves for the example presented.

Care must be exercised in using quantitative formulation to assure that the total exposure reduction, whether a one-time saving or years of repetitive savings, is considered and that realistic costing is used. Detailed formulation may be found in Regulatory Guide 1.110, "Cost-Benefit Analysis for Radwaste Systems for Light-Water-Cooled Nuclear Power Reactors", and in other published reports (NUREG/CR-0446 1979; Kathren et al. 1980; Fleishman and Clark 1982; IAEA 1979). 
Table 1. Calculated values for optimization example

\begin{tabular}{crrrc}
\hline $\begin{array}{c}\text { Shield } \\
\text { Thickness, } \\
\text { m }\end{array}$ & $\begin{array}{c}\text { Cost of } \\
\text { Detriment, } \\
\$\end{array}$ & $\begin{array}{c}\text { Cost of } \\
\text { Protection, } \\
\$\end{array}$ & $\begin{array}{c}\text { Total } \\
\text { Cost, } \\
\$\end{array}$ & $\begin{array}{c}\text { Cumulative } \\
\text { Dose, } \\
\text { person-rem }\end{array}$ \\
\hline 0.05 & 82,216 & 6,552 & 88,768 & 9.38 \\
0.1 & 40,827 & 13,104 & 53,931 & 4.66 \\
0.205 & 9,387 & 26,863 & 36,250 & 1.07 \\
0.3 & 2,482 & 39,312 & 41,794 & 0.28 \\
0.4 & 612 & 52,416 & 53,028 & 0.07 \\
0.5 & 150 & 65,520 & 65,870 & 0.02
\end{tabular}

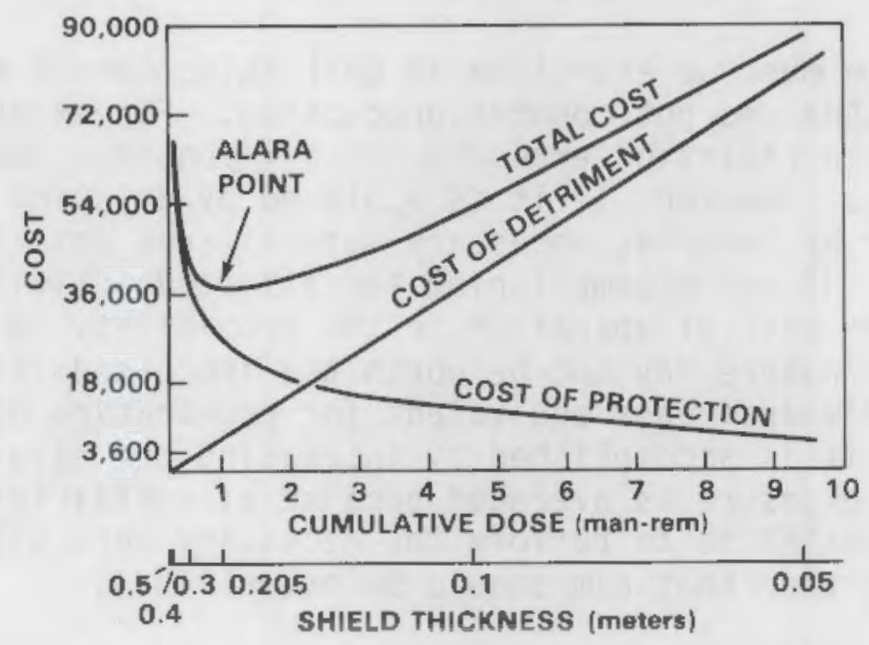

\section{FIGURE 2. ALARA curve for optimization example}

The ICRP-suggested optimization process $c$ an be an extremely valuable tool for evaluating ALARA activities and should be used whenever possible. Some ALARA activities (e.g., pre-job briefings, plan reviews to assure availability of materials, equipment and resources, and individual worker task knowledge verifications) may be difficult to quantify. However, these activities may be significant long-term contributors to exposure reduction. Hence, the extra effort required for their quantification may be worthwhile.

The quantitative information possible from using this optimization process will assist a 1 icensee's continuous efforts to identify exposure reduction opportunities. This, in turn, will enhance a facility's ability to effectively implement and evaluate the performance of its ALARA program.

PROGRAM EVALUATION

The performance of the ALARA program should be periodically reviewed by those directly responsible for its implementation and by management. The program should be evaluated based upon the objectives stated by management, 
its performance in meeting the goals established and the overall effectiveness in reducing exposure used in comparison with necessary work performed. The key to program evaluation is establishing specific goals, determining the program elements to be used to accomplish those goals, defining the methods of measurement, and frequently analyzing progress. Senior management commitment to the program and appropriate attention to progress is essential to successful implementation.

Goal Establishment

Goals should be established to effectively implement exposure reduction activities as well as to provide the incentive to implement ALARA and to use as a measure of achievement of ALARA. Each goal must be specific to the activity, clearly defined, measurable, realistic, fully understood, and agreed to by those responsible for both evaluation and achievement.

In addition, care must be exercised in goal selection to ensure that the ultimate result is ALARA and not counter-productive. For example, some percentage reduction in radiation exposure for a licensee's operation may be established as a goal. However, if it is achieved by delaying or canceling needed maintenance or by reducing necessary surveillance activities, it may not be ALARA at all. If not accomplishing the affected activities would increase the hazard or risk of operation or the probability of accident, the immediate saving of exposure may not be worth the increased risk. Likewise, reducing the mean individual dose equivalent for penetrating dose to the whole body is not ALARA if it is accomplished by increasing the size of the work force over which the exposure is averaged because of inefficiencies of extra workers. The aim of ALARA is to perform the necessary work with optimal exposure; goals to further that aim should be established.

Realistic ALARA goals may be developed using comparisons among groups performing the same work, among separate operations of the same task, among facilities performing the same or similar activities, among different methods of performing work, or just doing a given task with less exposure than previously. For example, an analysis and comparison of operator exposure used in performing pipe weld radiography, if weighted for number of radiographs performed, may show a marked difference in techniques of workers performing the work and alert management to the need for review. An ALARA review may then indicate the actions needed to reduce the exposure used. The possible actions include procedure revision, operator training, addition of collimators or other corrective changes.

It is essential for goal development, as well as for adequate work planning, exposure optimization, and trend analysis, that documentation of facility radiological conditions, work activity and personnel doses, results of dose reduction practices and optimization evaluations be completed, collected, and made available for review and use. 
Nonexposure goals may also be appropriate as part of the ALARA effort. For example, training of personnel in radiation protection and ALARA by a specific date, or holding pre-work briefings for all nonroutine radiation work, may be ALARA goals. As goals are met, new goals may need to be established to ensure continued ALARA effort. However, it should be recognized that, for a given task, exposure may not continually be reduced year after year. A low exposure may be reached for which further reductions are not justified.

\section{Measurement}

The specific parameters to be measured and the instrumentation and techniques used for measurement will depend upon the function of the licensee operation; the quantity, physical state, and kinds of radionuclides used; the size, type and purpose of radiation-generating equipment; and the levels of radiation exposure which workers and the public may receive. Specific requirements are identified by the various regulatory groups such as the NRC and the EPA in 10 CFR 50, 40 CFR 190, and 40 CFR 192. Guidance is provided in many publications issued by the ICRP (1968), NCRP (1978), and IAEA (1973, 1979), as well as in ANS I N 13.1-1969, ANS I N 343-1978, and ANS I N 323-1978. Identification and definition of necessary measurements and instrumentation and techniques to be used are beyond the scope of this document. However, it must be emphasized that the accurate, precise and reliable measurement of radiological conditions (radiation levels, personnel doses, airborne radioactivity concentrations, contamination levels, etc.) provides the foundation for controlling radiation and for verifying the achievement of the goals of radiation protection, compliance with regulatory requirements and reduction of radiation exposure to as low as reasonably achievable. The radiological parameters being measured and the methods of measurement will need to be periodically reviewed to be sure that the correct parameters are being measured and that the accuracy and sensitivity of the measurements are adequate for their intended purpose.

\section{Administrative Control Levels}

The basic objective of a radiation protection program is to reduce radiation exposures to workers and the public as low as reasonably achievable to reduce the level of risk. To assure that this basic objective is met, administrative controls should be established at levels substantially below the regulatory limits to alert management of conditions so that actions can be taken to provide additional surveillance and control.

The administrative control levels (or reference levels) may be a tiered system using specified levels as alerting points for predetermined actions. One such system of authorized limits (ICRP 1977, PP. 28-29) uses recording levels, investigation levels, and intervention levels that are established according to the following definitions:

- Recording level - That level of dose equivalent or intake above which the result is of sufficient interest to be worth recording and keeping. Conversely, if the results are below this level, the results can be covered by a simple statement that they were below the defined recording level. 
- Investigation level - That level of dose equivalent or intake above which the results are considered sufficiently important to justify further investigations.

- Intervention level - That level of dose equivalent or intake considered sufficiently important that intervention and additional control are necessary to prevent exceeding established limits.

Selection of numerical values for each level should be based on regulatory requirements and the level of control determined necessary by management. A commonly used and recommended investigation level is $10 \%$ of the allowable NRC dose. Radiation exposures meeting or exceeding this level would trigger an investigation by qualified personnel. Depending on the normal radiation exposure received performing the particular activity, the results of the investigation may be simple documentation that the investigation was made, methods of exposure reduction were considered and continued vigilance would be maintained. In other instances, the investigation may result in revision of work practices and procedures, addition of shielding or removal of sources of exposure, retraining of personnel, and added surveillance of the activity to provide more strict control. In all instances, it is necessary that an investigation be made by personnel qualified to evaluate the radiation protection being provided, to assess the adequacy of ALARA practices being used and to recommend actions to reduce exposure usage.

The use of quantitative techniques in selecting which exposure reduction action to take or in determining if additional reduction is warranted should be encouraged.

\section{Trend Analysis}

In addition to the administrative levels, trend analysis is an important ALARA tool. Trend analysis is especially useful for determining and anticipating the effects of actions that may, of themselves, appear to cause no noticeable change or cause changes that may be hidden within individual number fluctuation. Many radiological parameters recorded as part of a routine radiation protection program should be followed and analyzed for trends. Some particularly useful parameters(a) include:

1. mean individual dose equivalent for penetrating dose to the whole body

2. mean individual dose equivalent for nonpenetrating dose to the whole body

3. mean dose equivalent by radiation type

4. ratio of dose from different types of radiation

5. mean individual extremity dose

(a) Selected items on this 1 ist were taken from Kathren et al. (1980, pp. $10.25-10.26$ ). 
6. specific organ doses from external or internal sources

7. statistical distribution of mean individual dose

8. cumulative penetrating dose equivalent to the whole body(a)

9. cumulative nonpenetrating dose equivalent to the whole body(a)

10. mean individual dose equivalent by job classification(a)

11. mean individual dose equivalent by 1 ocation(a)

12. mean individual dose equivalent by task(a)

13. cumlative whole-body or organ dose to the general public

14. radiation area size

15. contaminated area size

16. contamination levels in an area

17. airborne activity concentrations

18. effluent release quantities and types

19. frequency of investigations and severity of occurrences.

Not all of these measures will be applicable at all facilities; in others, this list could be expanded to include additional items. However, several of the measures will be applicable to every activity and should be followed and analyzed for potential ALARA actions.

\section{AUDIT ING THE ALARA PROGRAM}

In addition to the analysis and evaluation of the ALARA progran conducted by those responsible for its implementation, an independent assessment should be performed to evaluate the effectiveness of the program and to verify that, when warranted, necessary corrective action is taken. The extent of the assessment and the resources allotted to it will be dependent upon the level of radiation resulting from the licensee's operation. However, an independent audit is essential for all operations.

As a minimum, the ALARA program should be audited once per year and the results documented and transmitted to the licensee's senior management. More frequent assessments may be desirable to inform management of program status or in operations where high exposure use or significant potential hazards may benefit from additional overview.

(a) Can also be used as a rate; viz. cumulative dose equivalent per hour worked. 
These program appraisals or audits should be conducted by qual ified personnel who are independent of those responsible for implementing the program. In addition, the personnel assigned this function should be selected based on their technical knowledge of the operations being observed, and their technical competence and experience in radiation protection and ALARA.

The specific qualifications of personnel performing this function may vary depending upon the level of hazard of the operation being assessed and upon the resources available for the assessment. As a minimum, the appraiser(s) should 1) have one year of experience associated with the operation being observed and be knowledgeable in the techniques being used; 2) be qualified in radiation protection similar to that defined in ANSI/ANS 3.1-1978 (i.e., the individual shall have a bachelor's degree or the equivalent in a science or engineering subject, including some formal training in radiation protection) and have at least five years of professional experience in applied radiation protection; and 3 ) be organizationally independent from those responsible for implementing the radiation protection and ALARA programs.

The audit process should review the total ALARA program and assess its effectiveness in meeting the stated objectives. The assessment should include detailed reviews of individual and collective exposure and those actions taken to ensure exposure optimization. Each element of the program, from the management commitment through the internal audit program, should be examined to verify that it has been included in the ALARA program, to assure that it has been implemented, and to assess its effectiveness.

Special attention should be given to the activities of the review committee and/or ALARA coordinator and to the reports resulting from exposures reaching or exceeding investigation levels. The corrective actions specified or recommended should be assessed for adequacy, timeliness, and effectiveness.

In addition, the auditors should review the procedures and the procedure review and approval process to verify that ALARA considerations are incorporated and that the procedure process assures continual consideration. The performance of personnel in exposure-related activities should be assessed to verify that ALARA training has been provided and that a working understanding of the ALARA concept and techniques for implementation has been demonstrated.

The program assessment report should describe program adequacy, implementation, and effectiveness, and should include recommendations for improvement. The report should be formalized in writing and presented to the licensee's senior management. It is essential to continued effectiveness of an ALARA program that the cycle of program definition, implementation, assessment, feedback and redefinition be repeated. The independent assessment provides an objective evaluation to management, who should then provide redefinition of the program objectives and goals as feedback to those responsible for program implementation. This redefinition should include corrective actions for weaknesses identified. This feedback will assure continual management attention and support for ALARA efforts. 


\section{REFERENCES}

ANS I/ANS 3.1-1978, "American National Standard for Selection and Training of Nuclear Power Plant Personnel," American National Standards Institute/American Nuclear Society.

ANSI N 13.1-1969, "Guide to Sampling Airborne Radioactive Materials in Nuclear Facilities," American National Standards Institute.

ANSI N 323-1978, "Radiation Protction Instrumentation Test and Calibration," American National Standards Institute.

ANS I N 343-1978, "Standard for Internal Dosimetry for Mixed Fission and Activation Products, "American National Standards Institute.

Fleishman, A. B., and M. J. Clark. 1982. "Evaluating Future Detriment from Radioactive Discharges: Judgments and Implications for Optimisation of Protection." National Radiological Protection Board, Chilton, Didcot, oxon, Great Britain.

International Atomic Energy Agency (IAEA). 1973. Radiation Protection Procedures. Safety Series No. 38, Vienna, Austria.

International Atomic Energy Agency (IAEA). 1979. Advances in Radiation Protection Monitoring. Proceedings of a symposium, June 20-30, 1978, Stockholm, Sweden.

International Atomic Energy Agency (IAEA). 1979. Application of the Dose Limitation System for Radiation Protection: Practical Implications. Proceedings of a seminar, March 5-9, 1979, Vienna, Austria.

International Atomic Energy Agency (IAEA). 1979. Radiological Surveillance of Airborne Contaminants in the Working Environment. Safety Series No. 49, Vienna, Austria.

International Commission on Radiological Protection (ICRP). 1968. General Principles of Monitoring for Radiation Protection of Workers. ICRP Publication 12, Pergamon Press, Oxford, Great Britain.

International Commission on Radiological Protection (ICRP). 1977. Recommendations of the International Commission on Radiological Protection. ICRP Publication 26, Pergamon Press, Oxford, Great Britain.

Kathren, R. L., R. C. Yoder, A. E. Desrosiers, N. D. Nisick, E. E. Oscarson, D. R. Mulhern, W. P. Howell, and D. A. Waite. 1980. A Guide to Reduc ing Radiation Exposure to As Low As Reasonably Achievable (ALARA). DOE/EV/1830-T5, U.S. Department of Energy, Division of Operational \& Environmental Safety, Washington, D.C. 
National Council on Radiation Protection and Measurements (NCRP). 1978. Operational Radiation Safety Program. NCRP Publication 59, Washington, D.C.

National Council on Radiation Protection and Measurement (NCRP). 1954. Permissible Dose from External Sources of Ionizing Radiation. National Council on Radiation Protection and Measurement, Washington, D.C.

National Radiological Protection Board. 1982. Cost Benefit Analysis in the Optimisation of Protection of Radiation Workers: A Consultative Document. Chilton, Didcot, Oxon, Great Britain.

NUREG/CR-0446, "Determining Effectiveness of ALARA Design and Operational Features," United Nuclear Industries, April 1979.

Voilleque, P. G., and R. A. Pavlick. 1982. "Societal Cost of Radiation Exposure." Health Physics. 43(3): 405-409. 


\section{B IBL IOGRAPHY}

ANS I/ANS 15.12-1977 (N647), "Design Objectives for and Monitoring of Systems Controlling Research Reactor Effluents," American National Standards Institute/American Nuclear Society.

ANS I/ANS 57.7-1981, "Design Criteria for an Independent Spent Fuel Storage Installation (Water Pool Type)," American National Standards Institute/American Nuclear Society.

ANSI/ANS-HPSSC 6.8.1-1981, "Location and Design Criteria for Area Radiation Monitoring Systems for Light Water Nuclear Reactors," American National Standards Institute/American Nuclear Society.

ANS I N 43.1-1969, "Radiological Safety in the Design and Operation of Particle Accelerators," American National Standards Institute.

ANS I N 43.2-1971, "Radiation Safety for X-ray Diffraction and Fluorescence Analysis Equipment," American National Standards Institute.

ANS I N 305-1975, "Design Objectives for Highly Radioactive Sol id Material Handling and Storage Facilities in a Reprocessing Plant," American National Standards Institute.

ANS I N 433.1-1977 (Draft April 1, 1977), "Safe Design and Use of SelfContained, Dry Source Storage Gamma Irradiators (Category I)," American National Standards Institute.

ANS I N 431-1979 (Draft May 30, 1979), "Radiological Safety for the Design and Construction of Apparatus for Gamma Radiography," American National Standards Institute.

ANS I 101.3-1979, "Guide to Principal Design Criteria for Nuclear Fuel Reprocessing Facilities," American National Standards Institute.

ANS I N 42.12-1980, "Calibration and Usage of Sodium Iodide Detector Systems," American National Standards Institute.

Standards for Protection Against Radiation, 10 CFR 20.1 (c), revised January 1, 1971.

Standards for Protection Against Radiation, 10 CFR 20.1 (c), revised January 1976.

EPA 80-1, "Cost-Risk Analyses of Protective Actions for a Low-Level Deposition of Radionuclides," Environmental Protection Agency, 1980.

EPA 600/5-74-006, "Environmental Impact Requirements in the States: NEPA's offspring," Environmental Protection Agency, 1974. 
EPA 625/6-78-004, "Industrial Guide for Air Pollution Control," Environmental Protection Agency, 1978.

International Commission on Radiological Protection (ICRP). 1973. Implications of Commission Recommendations that Doses Be Kept As Low As Readily Achievable. ICRP Publication 22, Pergamon Press, 0xford, Great Britain.

International Commission on Radiological Protection (ICRP). 1977. Problems Involved in Developing an Index of Harm. ICRP Publication 27, Pergamon Press, 0xford, Great Britain.

International Commission on Radiological Protection (ICRP). 1978. The Principles and General Procedures for Handling Emergency and Accidental Exposures of Workers. ICRP Publication 28, Pergamon Press, 0xford, Great Britain.

Institute for Nuclear Power Operations (INPO). 1982. ALARA Planning for Station Work. INP0 82-001-0EN-08A, September 1982.

Kathren, R.L. 1982. "Management Organization and Administration for ALARA." Health Physics. 42(2): 119-131.

National Council on Radiation Protection and Measurements (NCRP). 1978. A Handbook of Radioactive Measurements Procedures. NCRP Publication 58, National Council on Radiation Protection and Measurements, Washington, D.C.

NUREG-0267, "Principles and Practices for Keeping Occupational Radiation Exposures at Medical Institutions As Low As Reasonably Achievable," October 1982.

NUREG-0761, "Radiation Protection Plans for Nuclear Power Reactor Licensees," Draft, March 1981.

NUREG-0880, "Safety Goals for Nuclear Power Plants: A Discussion Paper," February 1982.

Radiation Protection Optimization, Present Experience and Methods. Proceedings of the European Scientific Seminar, October 3-5, 1979, Luxembourg. Pergamon Press, Oxford, Great Britain.

Regulatory Guide 1.8, "Personnel Qualification and Training," Second Proposed Revision 2, Task RS 807-5, September 1980.

Regulatory Guide 3.5, "Standard Format and Content of License Applications for Uranium Mills," Draft Revision 2, Task WN 039-4, August 1981.

Regulatory Guide 4.14, "Radiological Effluent and Environmental Monitoring at Uranium Mills," April 1980. 
Regulatory Guide 8.8, "Information Relevant To Ensuring That Occupational Radiation Exposures At Nuclear Power Stations Will Be As Low As Reasonably Achievable (ALARA)," Proposed Revision 4, Task OH 507-4, March 1979.

Regulatory Guide 8.15, "Acceptable Programs for Respiratory Protection," October 1976.

Regulatory Guide 8.18, "Information Relevant To Ensuring That Occupational Radiation Exposures at Medical Institutions Will Be As Low As Reasonably Achievable," October 1982.

Regulatory Guide 8.27, "Radiation Protection Training for Personnel at LightWater-Cooled Nuclear Power Plants," March 1981.

Regulatory Guide 8.31, "Information Relevant to Ensuring That Occupational Radiation Exposures at Uranium Mills Will Be As Low As Is Reasonably Achievable," May 1983.

Regulatory Guide 8.30, "Health Physics Surveys in Uranium Mills," May 1983. 


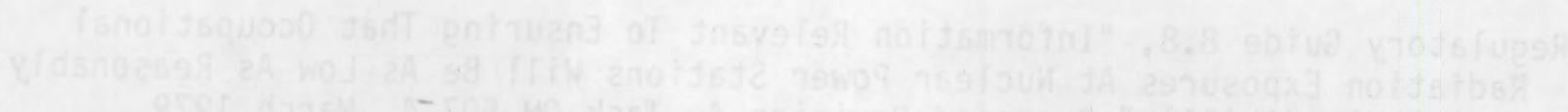

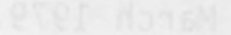

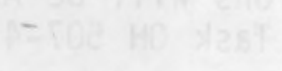

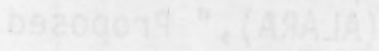

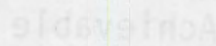

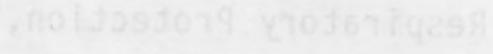

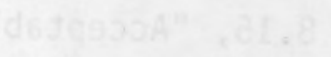

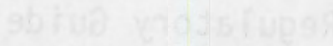

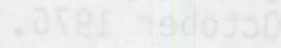

16not369uazo

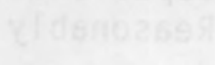

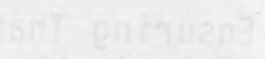

(2)

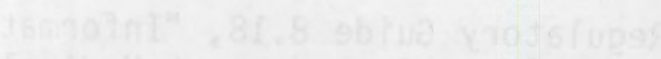

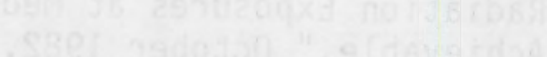

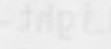

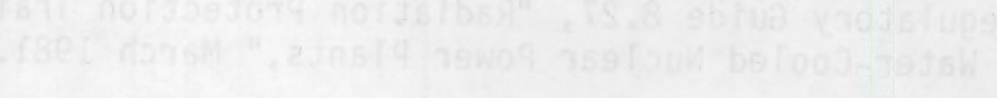

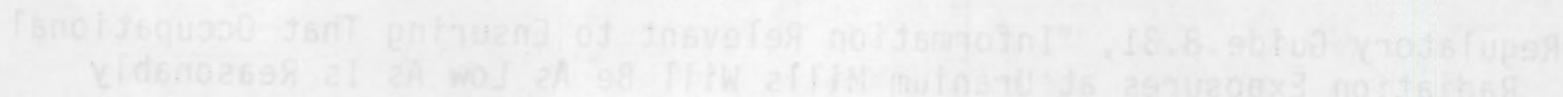

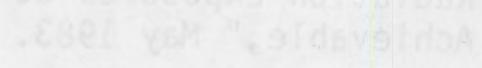

$3002 x^{3}$

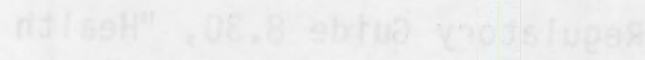




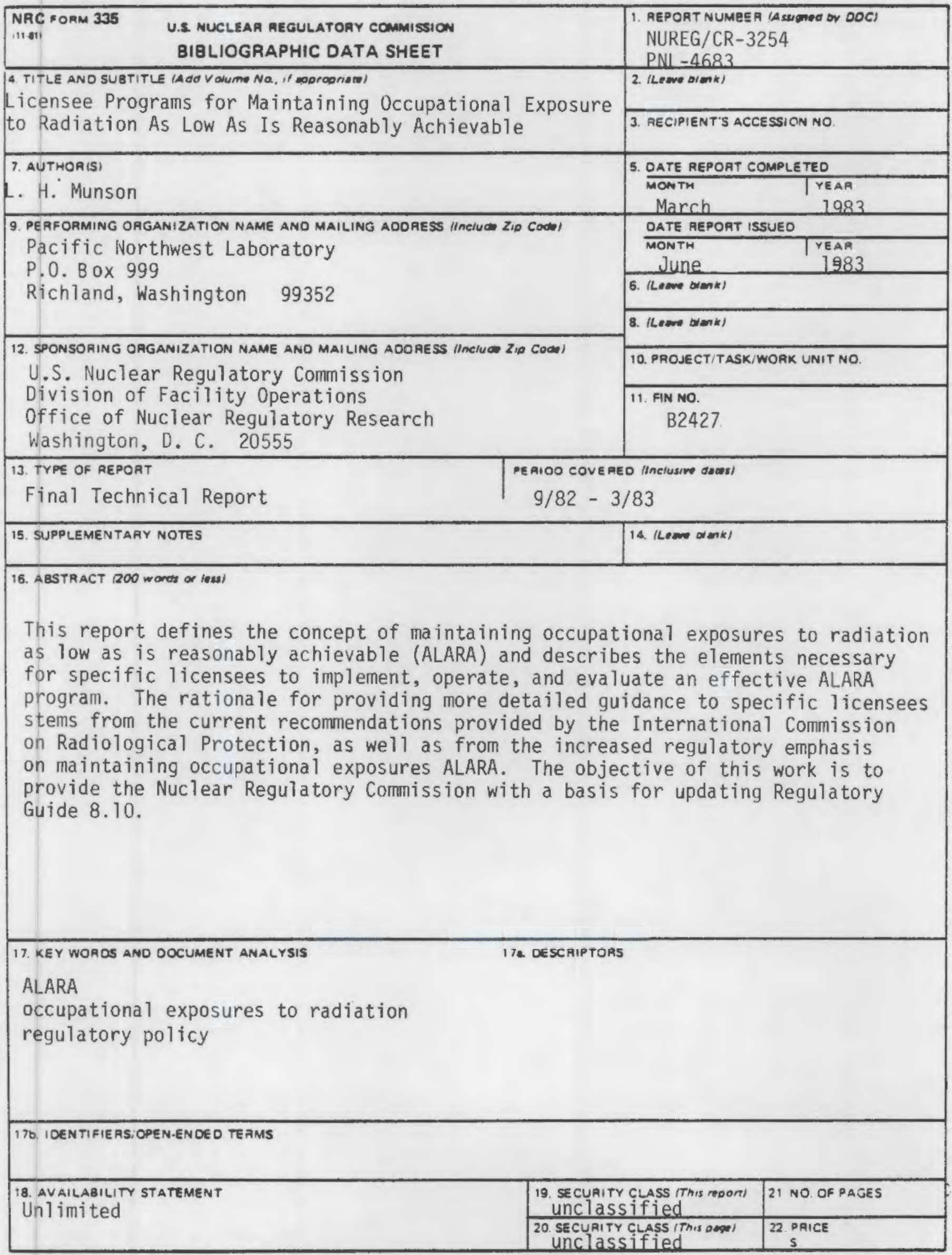


